Japan. J. Med. Sci. Biol., 29, 199-210, 1976

\title{
A SUGGESTED ROLE OF A HOST-PARASITE LIPID COMPLEX IN MYCOBACTERIAL INFECTION
}

\author{
Eiko KONDO and Koomi KANAI \\ Department of Tuberculosis, and The First Department of Bacteriology, \\ National Institute of Health, Shinagawa-ku, Tokyo 141, Japan
}

(Received: March 16, 1976)

\begin{abstract}
SUMMARY : On the basis of our previous observations and related literatures, we assumed that cholesterol esters of host origin and phthiocerol dimycocerosate of bacterial origin are located as a lipid mixture around the periphery of pathogenic mycobacteria growing in vivo, probably within the phagocytic vacuole of macrophages.

To examine the role of such a postulated lipid complex in mycobacterial infection, a model experiment was made in which tubercle bacilli grown in vitro were "coated" with both lipids and then suspended homogenously in water to serve as an inoculum to infect mice intravenously. Their fate in mouse tissue was compared with that of untreated control bacilli.

The results indicated that the lipid-"coating" had an infection-promoting effect as revealed by the longer persistence of the treated avirulent bacilli at higher levels of viable counts.

When virulent tubercle bacilli were "coated" with the lipid mixture, they became less sensitive to the protective mechanism of BCG-immunized mice.
\end{abstract}

\section{INTRODUCTION}

We have been concerned ourselves with lipid chemistry of tuberculous lesions, mycobacteria-infected macrophages, and mycobacteria grown in vivo (Kondo and Kanai, 1972, 1974, 1976c). One of the findings obtained from these studies was that cholesterol esters were accumulated in the infected macrophages and the esters were closely associated with the bacilli.

An accompanied observation was that phthiocerol dimycocerosate (DIM) was present in the in vivo-grown mycobacteria as one of the main lipid components (Kondo and Kanai, 1972). This lipid is characteristic of M. tubeculosis and $M$. bovis and classified as one related to mycosides (the type-specific mycobacterial glycolipid) despite the lack of sugar moiety (Smith et al., 1960). Their possible surface location in mycobacteria grown in vitro and in vivo has been pointed out by Goren (1972) and Draper and Rees (1973). In this regard, we postulated a situation that DIM may be present around tubercle bacilli staying within the phagocytic vacuole of macrophages in the same manner as described 近藤犖子（国立予防衛生研究所 結核部）金井興美（国立予防衛生研究所・細菌第一部） 
by Draper and Rees (1973) concerning mycoside C of murine leprosy bacilli.

If this was the case, DIM should have a close association with cholesterol esters accumulated around the bacilli, because both lipids are highly hydrophobic and their melting points are near the body temperature. As a matter of fact, free cholesterol, its esters, and DIM constituted the major portion of neutral lipids extracted from $M$. bovis grown in vivo (Kondo and Kanai, 1972).

The present study is to determine whether or not a host-parasite lipid complex as suggested above plays a role in the development of mycobacterial infection.

\section{Materials ANd Methods}

Animals: Mice were of commercially available ddY strain, male, albino and weighing around $20 \mathrm{~g}$. Every 10 mice were housed in a metal cage with a wire-grid top floored with wood shavings. They were fed with pellet diet and water. Guinea pigs were of a random-bred strain, albino, male, and weighing around $600 \mathrm{~g}$ in the average. Every five animals were housed in a metal cage and fed with pellet diet and water.

Micro-organisms: M. tuberculosis (H37Rv and H37Ra), M. bovis (Ravenel and BCG), and $M$. phlei were the micro-organisms employed. They have been maintained on Sauton synthetic liquid medium. Except $M$. phlei and BCG, their kanamycin-resistant substrains were used for technical convenience as described later.

Enumeration of viable units in infected mouse organs: Mice were sacrificed by cervical dislocation, and the lung and the spleen were removed. The organs were weighed and their surface was washed with sterilized distilled water. Each washed organ was placed into a mortar and homogenized to prepare a 1:10 dilution in distilled water. The homogenate was allowed to pass through a sheet of gauze. When required, serial 10-fold dilutions were prepared from the filtrate, and each dilution in an amount of $0.1 \mathrm{ml}$ was inoculated onto three slants of glycerol-egg medium (Ogawa type). The number of colonies developed after incubation at $37 \mathrm{C}$ for four weeks allowed calculation of viable units present in the tissue. The slants containing kanamycin in a concentration of $100 \mu \mathrm{g}$ per ml were employed for selective isolation of the kanamycin-resistant bacilli used as challenge inocula and for prevention of bacterial contamination. In the case of infection with $M$. phlei, the tissue homogenate was prepared with a $0.5 \% \mathrm{NaOH}$ solution.

Lipids: Phthiocerol dimycocerosate (DIM) was isolated from Ravenel strain grown on Sauton synthetic liquid medium. The Wax A fraction was obtained by the Anderson-Lederer procedure (Asselineau, 1962) and it was separated into individual lipids by chromatography on a Florisil-Celite column. DIM was 
eluted with benzene and identified with a known sample by thin-layer chromatography. The detailed method was described in our previous paper (Kondo and Kanai, 1972). Cholesteryl oleate and cholesteryl stearate were commercial products (Sigma).

Coating mycobacteria with lipids: DIM and cholesterol ester were each dissolved in $0.5 \mathrm{ml}$ of ether and placed into a mortar. The lipid mixture was left to stand allowing the evaporation of ether. The mycobacteria harvested from the growth on Sauton medium and partially dried by pressing between layered folds of absorbent papers was added to the lipids in an amount of 20 to $50 \mathrm{mg}$ (10 mg in the case of H37Ra strain) and ground well in the mortar. Then, distilled water was added drop-wise while grinding to prepare a fine homogenous suspension of desired bacillary concentrations.

\section{RESULTS}

\section{Effects of Coating with DIM, Cholesteryl Oleate, or Their Mixture on the Persistence of H37Ra and H37Rv Tubercle Bacilli in the Mouse Organs}

Four groups of mice were arranged, each consisting of 17. They were infected intravenously with $0.2 \mathrm{mg}$ of H37Ra tubercle bacilli uncoated or coated with DIM, cholesteryl oleate, or their mixture. The lipid treatment was made with $10 \mathrm{mg}$ of single lipid or with the combined lipids of equal $5 \mathrm{mg}$ to coat a 20-mg amount of the bacilli.

The next day of infection and then once a week for four weeks, three or four animals were sampled at random from each group and sacrificed for enumeration of viable units in the lungs. The results are summarized in Fig. 1. This figure shows one very impressive event that the avirulent bacilli, H37Ra, persisted keeping a definitely higher level of viable units when they were coated with both lipids, and that the coating with either single lipid did not produce such an effect.

To confirm the effect of the lipid mixture as above, the next experiment was undertaken with $\mathrm{H} 37 \mathrm{Ra}$ and $\mathrm{H} 37 \mathrm{Rv}$ strains. Four groups of mice each consisting of 20 were arranged to be infected intravenously with $0.5 \mathrm{mg}$ of uncoated or coated H37Ra bacilli and with $0.02 \mathrm{mg}$ of uncoated or coated H37Rv bacilli. In the case of H37Ra, a 50-mg amount of the cells was treated with $10 \mathrm{mg}$ of the lipid mixture ( $5 \mathrm{mg}$ DIM and $5 \mathrm{mg}$ cholesteryl oleate), and a $10 \mathrm{-mg}$ amount of $\mathrm{H} 37 \mathrm{Rv}$ bacilli was treated with the lipid mixture of the same amounts.

The fate of each of these four kinds of inoculum in the lung and spleen was followed up to the seventh week by the same procedure as the preceding experiments. The results are shown in Figs. 2 and 3. The coated H37Ra bacilli 

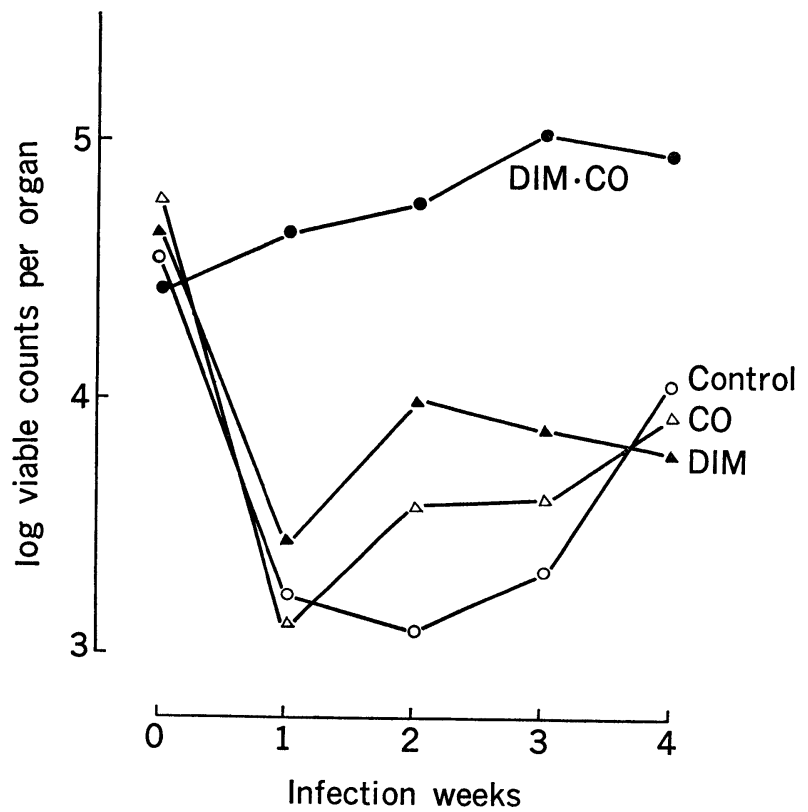

Fig. 1. Effects of coating with phthiocerol dimycocerosate (DIM), cholesteryl oleate (CO), or their mixture on the persistence of H37Ra tubercle bacilli in the mouse lungs.
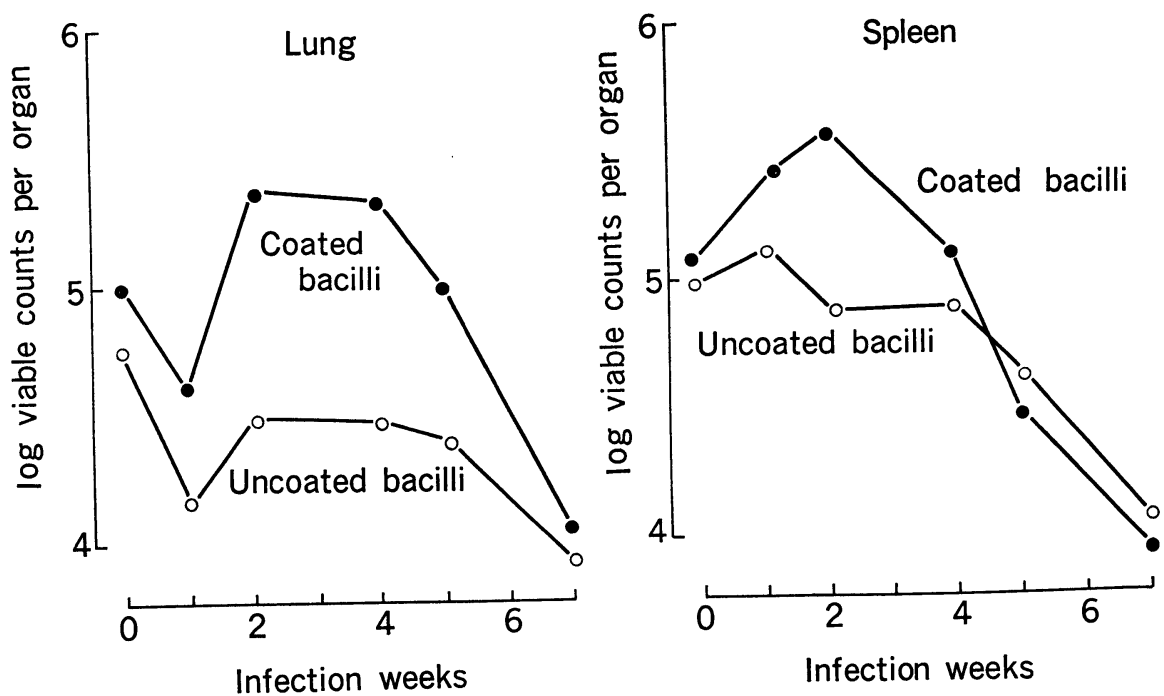

Fig. 2. Effect of coating with the mixture of DIM and cholesteryl oleate on the fate of H37Ra tubercle bacilli in the mouse lung and spleen. 

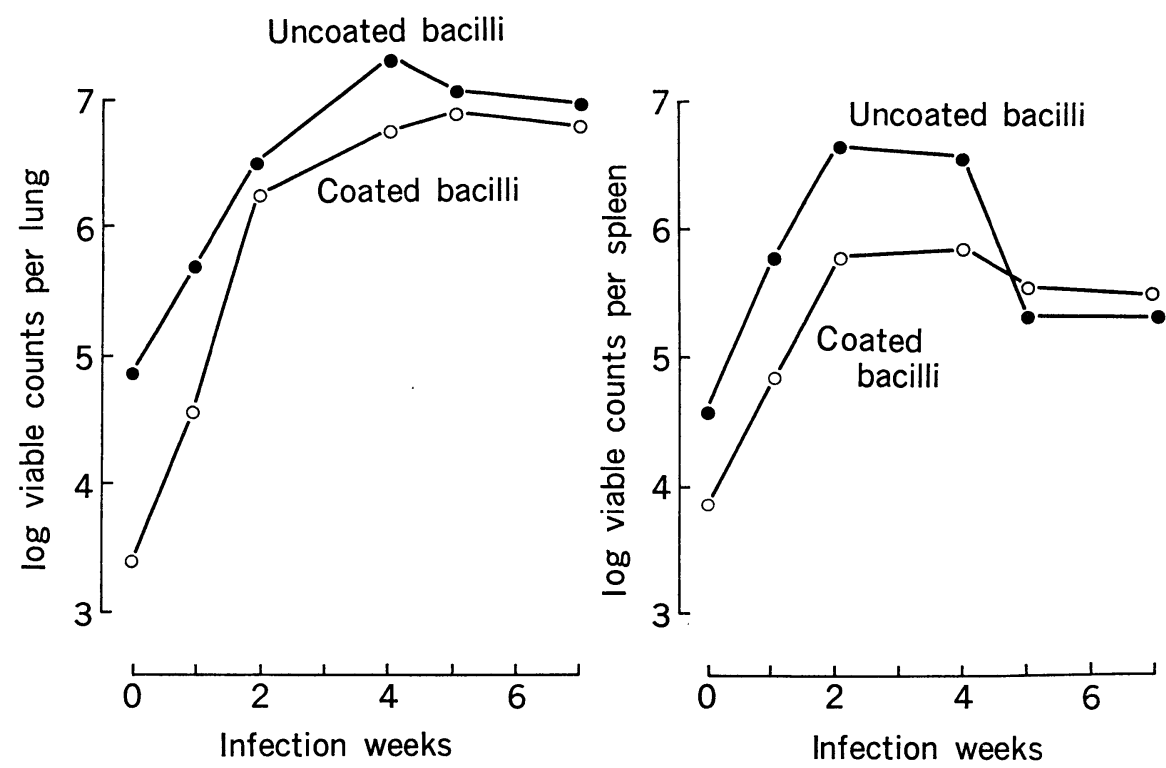

Fig. 3. Effect of coating with the mixture of DIM and cholesteryl oleate on the fate of H37Rv tubercle bacilli in the mouse lung and spleen.

also persisted with a higher level of viable counts than the uncoated bacilli in the lung and the spleen. The coating appeared to support multiplication of this avirulent strain to some extent. In the case of coated $H 37 \mathrm{Rv}$ tubercle bacilli, the number of implanted viable units in the lung and spleen was much smaller than the uncoated ones. Therefore, evaluation of the results shown in Fig. 3 is rather difficult. The virulent bacilli can elaborate DIM and cholesterol esters in the natural course of infection. Therefore, the artificial treatment of them with these lipids would not be so effective in modifying the infection as in the case of avirulent bacilli.

Interesting was an additional observation that the spleen weight of mice injected with the coated H37Ra increased greatly, whereas that of mice infected with the uncoated bacilli remained almost the same during the experimental period of 7 weeks (Exp. 1 in Fig. 4). Exp. 2 in Fig. 4 shows the results of a supplementary experiment to confirm the fact of spleen swelling as above. The experiment was conducted in such a design to compare the cases of coating with DIM plus cholesteryl oleate and those with DIM plus cholesteryl stearate. Besides, we included coating heat-killed H37Ra with DIM and cholesteryl oleate. As shown in Fig. 4, the spleen swelling by the coated H37Ra bacilli was confirmed regardless of the kind of cholesterol ester. However, the same amount of heat-killed H37Ra cells coated with DIM and cholesteryl oleate did not produce such an effect at all. The spleen swelling by the uncoated bacilli was 


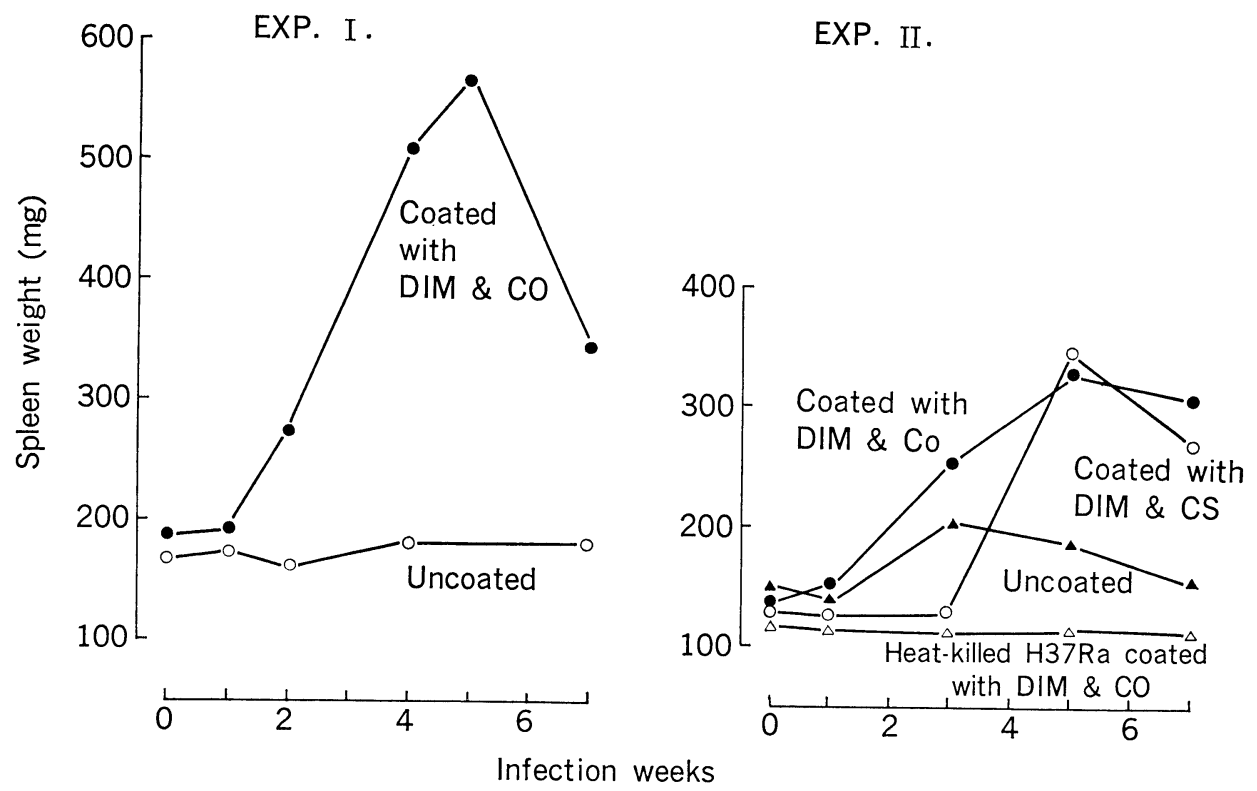

Fig. 4. Spleen swelling in the mice infected with H37Ra tubercle bacilli coated with the mixture of DIM and cholesteryl oleate (CO) or cholestryl stearate (CS).

moderate. These observations appear to suggest that the enhanced spleen enlargement might have been due to the interaction between the tissue and the coated living H37Ra cells.

Lastly, guinea pigs were also found to respond showing enhanced spleen swelling to intravenous injection with the coated bacilli. H37Ra bacilli were coated as usual with DIM and cholesteryl oleate and five animals were infected with $1 \mathrm{mg}$ of the treated bacilli. Three weeks after infection, they were sacrificed to weigh the spleen and compared with those of other five guinea pigs infected with the untreated bacilli.

The result was that the average spleen weight of the former animals was about twice as much as that of the latter.

\section{Effect of the Coating with DIM and Cholesteryl Oleate of Saprophytic Mycobacteria on Their Persistence in Mice}

M. phlei is a saprophytic species of mycobacteria which is rapidly removed from the host body. An attempt was made to examine the effect of coating with DIM and cholesteryl oleate on their persistence in the mouse lungs.

Fifty milligrams of the bacteria were treated with DIM and cholesteryl oleate, each in an amount of $5 \mathrm{mg}$. The treated mycobacteria were suspended in water 


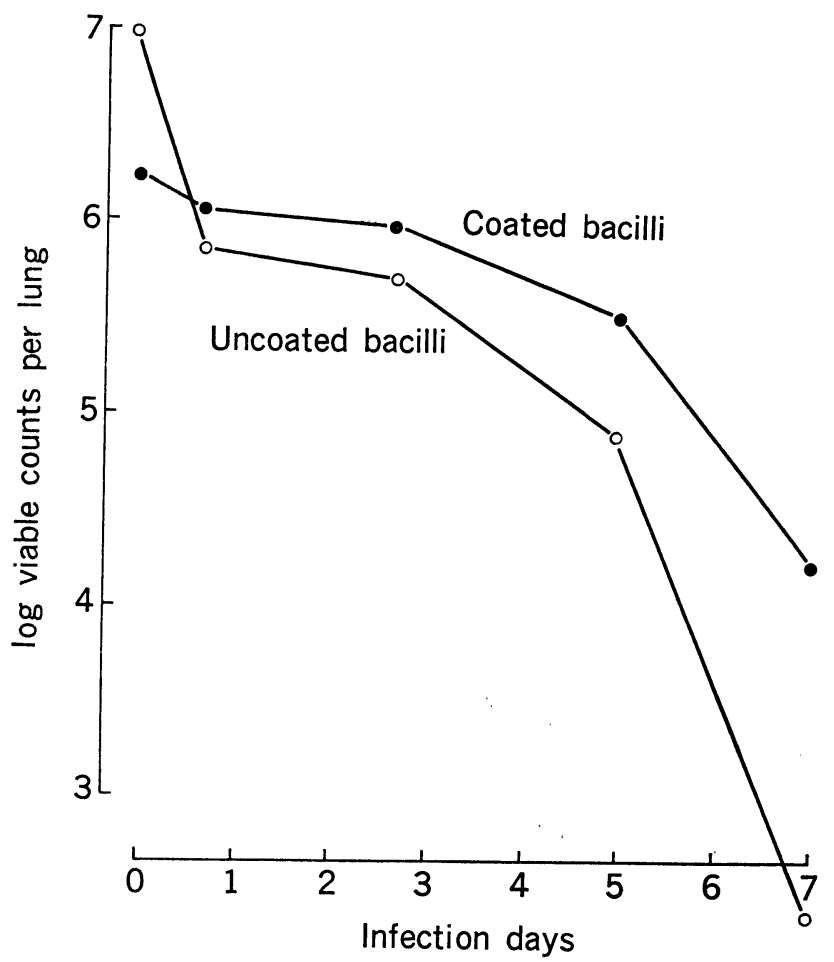

Fig. 5. Effect of coating with DIM and cholesteryl oleate of saprophytic mycobacteria (M. phlei) on their persistence in mice.

at a concentration of $5 \mathrm{mg} / \mathrm{ml}$. Fifteen mice were injected intravenously with , 0.3-ml quantities of this suspension. The same number of mice of another group were also injected similarly, but with untreated control mycobacteria.

Three hours and one day after infection, and then with two-day intervals, three mice were sampled at random from each group and sacrificed for enumeration of viable units in the lungs. The results are shown in Fig. 5. As shown here, the lipid coating delayed the disappearance of $M$. phlei from the lungs.

\section{Fate of Virulent Tubercle Bacilli (H37Rv) Uncoated or Coated with} DIM and Cholesteryl Oleate in Normal and BCG-Vaccinated Mice

As stated before, virulent tubercle bacilli can elaborate DIM and cholesterol esters in the natural course of infection. Probably because of this fact, the artificial coating of virulent tubercle bacilli with the both lipids did not produce any infection-promoting effect in our previous experiment (Fig. 3). In our next attempt, therefore, the effect of coating were examined in the early stage of infection comparing between normal and BCG-immunized mice. 

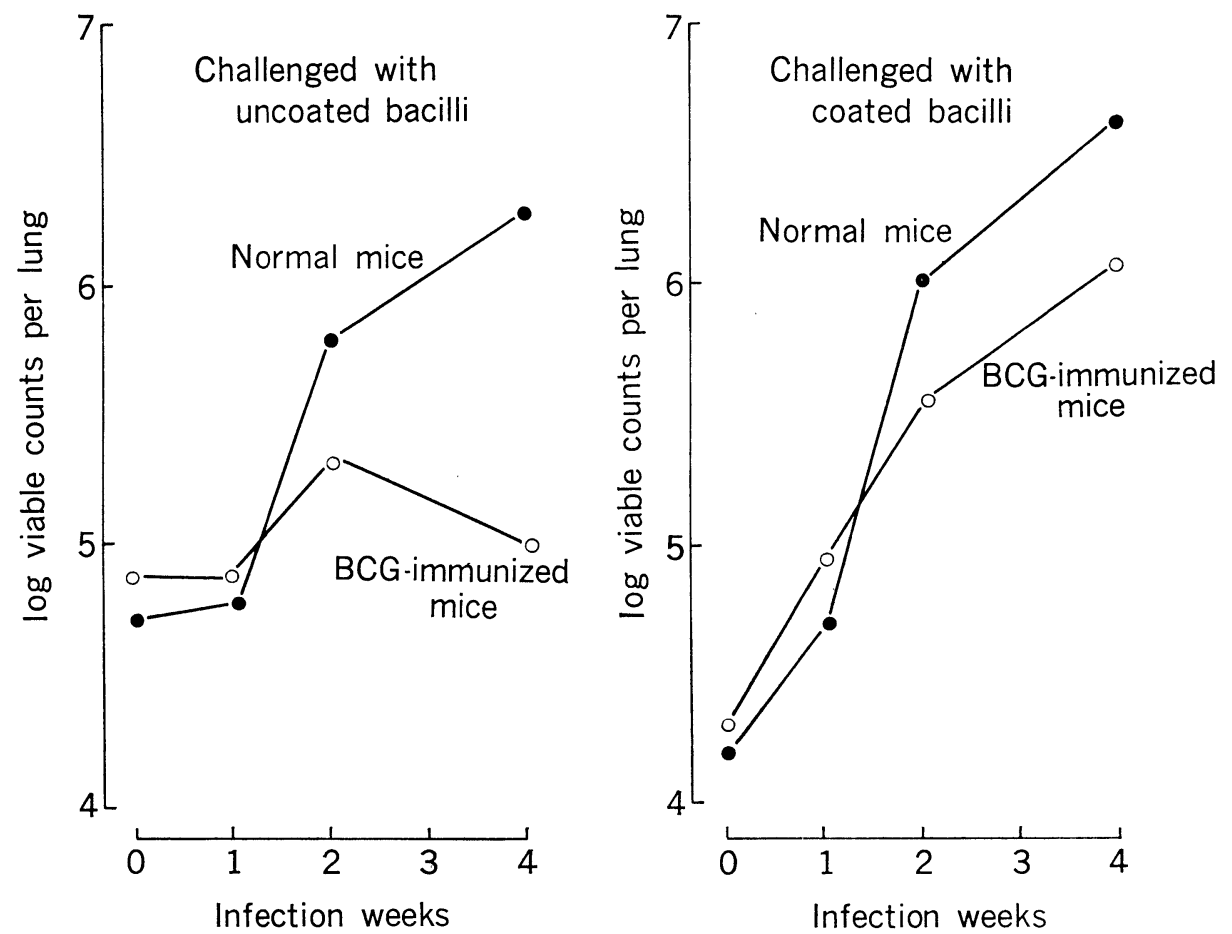

Fig. 6. Fate of virulent tubercle bacilli (H37Rv) uncoated or coated with DIM and cholesteryl oleate in normal mice and those vaccinated with BCG (viable counts in the lung).

Fifty mice were divided into two groups of equal 25, and the animals of one group were vaccinated intraperitoneally with BCG. Two weeks later, each of the two groups was divided into two subgroups of 12 and 13 mice to be challenged intravenously with $0.01-\mathrm{mg}$ doses of $\mathrm{H} 37 \mathrm{Rv}$ tubercle bacilli uncoated or coated with DIM and cholesteryl oleate. One day after infection and with one-week intervals, three mice were sacrificed at random from each of the four subgroups and sacrificed for enumeration of viable units in the lung and the spleen. The results are shown in Figs. 6 and 7 and the time-course change of spleen weight in Fig. 8. Figures 6 and 7 show the fact that, in BCG-immunized mice, the coated bacilli did not receive growth inhibition so markedly as did the uncoated bacilli. The coated bacilli continued to multiply in the lung of both the normal and immunized mice, though the level of viable counts was a little lower in the latter group of mice. On the other hand, the uncoated bacilli received a marked inhibition in the lung of immunized mice, showing a decline of viable counts in the period from the second to fourth weeks. Almost the same tendency as above was noted in the case of the spleen. An explanation for such a phenomenon may partially be obtained in Fig. 8. It shows that the 

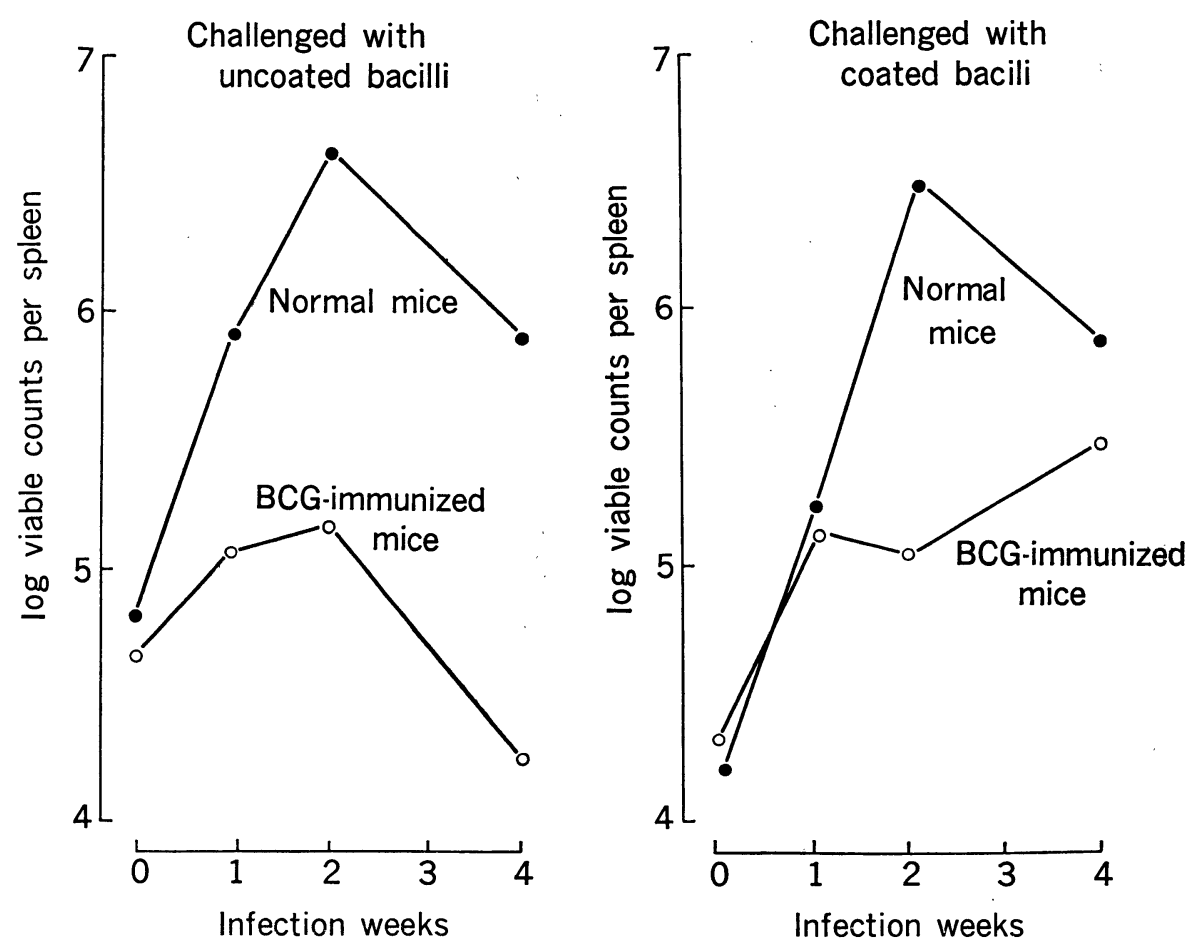

Fig. 7. Fate of virulent tubercle bacilli (H37Rv) uncoated or coated with DIM and cholesteryl oleate in normal mice and those vaccinated with BCG (viable counts in the spleen).

spleen enlargement of BCG-immunized mice in response to the challenge with the coated bacilli was one week delayed in its occurrence and much smaller in size than that in response to the uncoated bacilli. Perhaps, this means that when the challenge inoculum is coated with such a lipid mixture, the antigenic surface to stimulate the immune mechanism may be masked at least for some period after infection. Therefore, the immune mechanism does not begin to operate against them so promtly as against the uncoated bacilli.

\section{Absence of Adjuvant Activity in Cholesterol Esters to Enhance the Sensitizing Capacity of Heat-killed Mycobacteria}

Cholesteryl oleate has some physical properties similar to liquid paraffin; for instance, the melting point and the highly hydrophobic property. In this regard, we were interested in the possibility that cholesteryl oleate might be active as an adjuvant enhancing the sensitizing capacity of heat-killed tubercle bacilli.

Twenty guinea pigs were divided into four groups of equal five. Two 

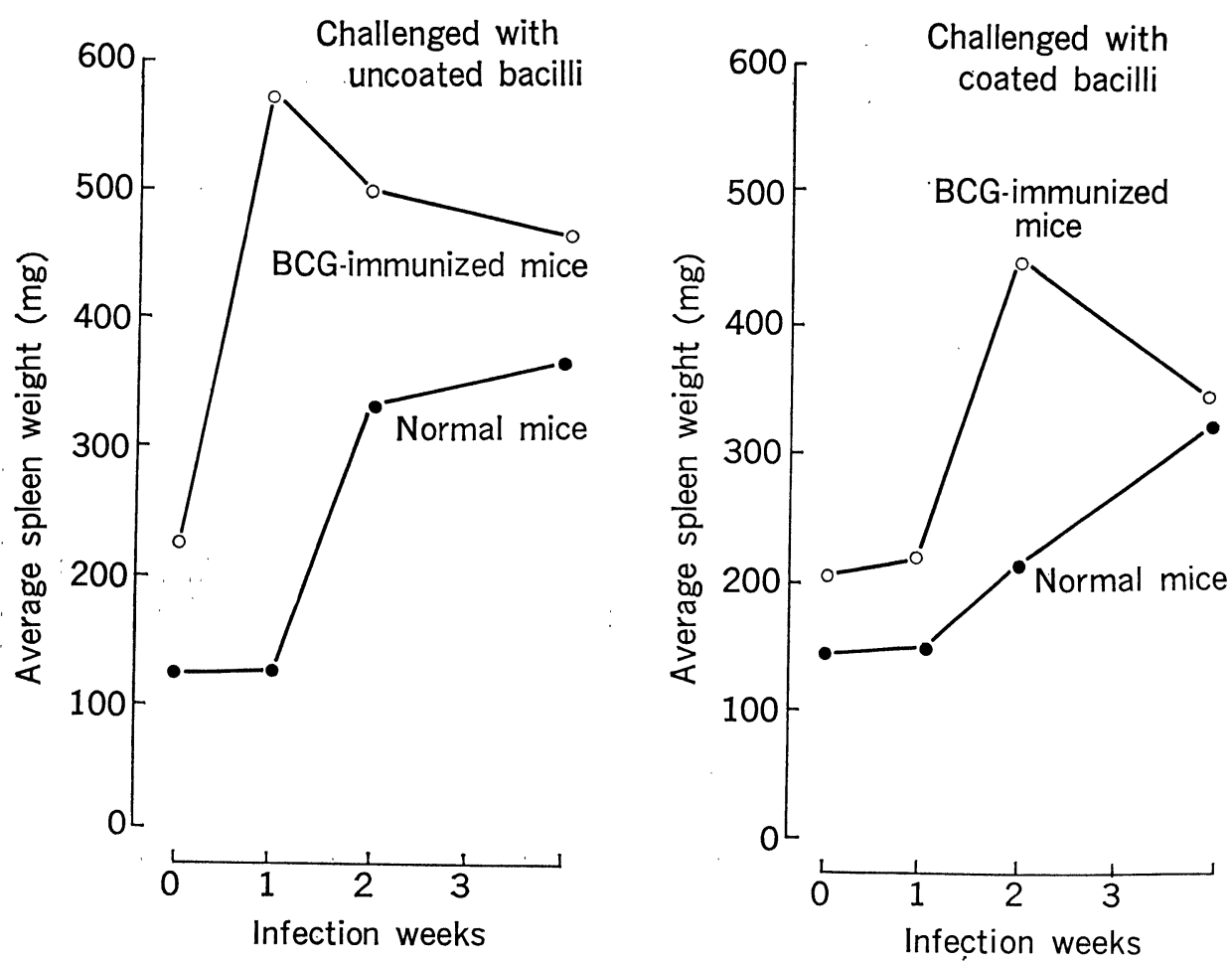

Fig. 8. Spleen enlargement in normal and BCG-immunized mice in response to virulent tubercle bacilli (H37Rv) uncoated or coated with DIM and cholesteryl oleate.

groups were vaccinated intramuscularly on the left thigh with heat-killed H37Ra tubercle bacilli treated with DIM and cholesteryl oleate or with DIM and liquid paraffin at $0.01 \mathrm{mg}$ doses. The animals of another group were simply vaccinated with the same amounts of untreated killed bacilli. The remaining group was left unvaccinated.

TABLE I

Absence of adjuvant activity of the DIM-cholesteryl oleate mixture on the sensitizing capacity of heat-killed H37Ra tubercle bacilli

\begin{tabular}{|c|c|c|c|c|c|c|}
\hline $\begin{array}{l}\text { Sensitized } \\
\text { with }\end{array}$ & \multicolumn{6}{|c|}{$\begin{array}{c}\text { Size }(\mathrm{mm} \times \mathrm{mm}) \text { of } 24 \mathrm{hr} \text { skin reactions elicited with } \\
1 \mu \mathrm{g} \text { of PPD in five guinea pigs }\end{array}$} \\
\hline None (Control) & & 0 & 0 & 0 & 0 & 0 \\
\hline $\begin{array}{l}\text { Heat killed } \\
\text { H37Ra bacilli } \\
(0.01 \mathrm{mg}) \\
\text { coated with }\end{array}$ & $\left\{\begin{array}{l}\text { DIM + cholesteryl oleate } \\
\text { DIM + liquid paraffin } \\
\text { None }\end{array}\right.$ & $\begin{array}{c}0 \\
13 \times 12 \\
0\end{array}$ & $\begin{array}{c}0 \\
12 \times 12 \\
0\end{array}$ & $\begin{array}{c}0 \\
15 \times 15 \\
0\end{array}$ & $\begin{array}{c}0 \\
14 \times 13 \\
0\end{array}$ & $\begin{array}{c}0 \\
13 \times 13 \\
0\end{array}$ \\
\hline
\end{tabular}

Three weeks after vaccination, each animal was skin-tested with $1 \mu \mathrm{g}$ of PPD; the elicited reactions were read at $24 \mathrm{hr}$ and expressed in diameters in $\mathrm{mm}$. 
The results are shown in Table I. As demonstrated here, cholesteryl oleate did not work as adjuvant unlike liquid paraffin. The animals vaccinated with the killed bacilli treated with DIM and cholesteryl oleate did not reveal any induration or redness at all.

\section{Discussion}

We have already described in the introduction the basic idea on which the present study was started. Such idea appears to have been rewarded positively with the findings that coating avirulent tubercle bacilli with DIM and cholesteryl oleate made them persist in the mouse tissue at a higher level of viable count, and that the coated virulent bacilli became less sensitive to the protective mechanism of BCG-immunized mice.

In the separate paper (Kondo and Kanai, 1976c) we will report that the ratio of ester to free cholesterol in the in vivo-grown mycobacteria was increasingly higher with the progress of their purification from the host tissue. This is an additional evidence to prove that cholesterol esters are more concentrated around mycobacteria growing in vivo than in the tissue environment, and most likely they are closely associated with the bacilli as the result of host-parasite interaction. Cholesterol-ester accumulation can occur in mycobacteria-infected macrophages (Kondo and Kanai, 1976b). Besides, it is known that Kupffer cells of the liver and splenic macrophages loaded with cholesteryl oleate did not prevent phagocytosis of other particles by those phagocytic cells (Stuart and Smith, 1974). These findings, together with the work of Werb and Cohn (1972) who demonstrated the intraphagosomal location of cholesterol esters, provide us a good reason to believe that cholesterol esters and mycobacteria can have a chance to associate mutually within the phagocytic vacuole of macrophages.

It must also be remembered that mycobacteria themselves have a capacity to esterify cholesterol to some extent as shown by us (Kondo and Kanai, 1976a) and other workers (Razin and Shafer, 1969; Schubert, Kaufman and Hörhold, 1969).

As for DIM, we have no direct experimental evidence to show that this is a surface lipid of mycobacteria. All that has been known is that DIM is a typespecific lipid to M. tuberculosis and M. bovis, and that it is classified into mycosides (type-specific mycobacterial glycolipids) despite the absence of sugar moiety. Mycosides are regarded as surface lipids since they are related with colony morphology and are qualified as phage-receptors (Fregnan, Smith and Randall, 1962; Randall and Smith, 1964; Fruchi and Tokunaga, 1972; Goren et al., 1972). Particularly, Draper and Lees (1973) demonstrated that the electron-transparent zone seen around the murine leprosy bacilli ingested into phagocytic vacuole of macrophages was a fibrillar material whose chemical nature is mycoside $\mathrm{C}$ (a 
peptidoglycolipid). In this regard, we postulated an analogous situation for DIM. In fact, DIM and related compounds were the main lipids of bovine mycobacteria grown in vivo (Kondo and Kanai, 1972). It amounted to $3.35 \%$ dried weight of the whole cell. As will be reported in detail elsewhere, this amount was larger than $2.10 \%$ of the same strain (Ravenel), $1.55 \%$ of H37Rv and $1.07 \%$ of $\mathrm{H} 37 \mathrm{Ra}$ all grown in vitro. These data, together with the recent paper of Goren, Brokl and Schaeffer (1974), may suggest that DIM is one of the lipids of putative relevance to virulence in $M$. tuberculosis.

\section{REFERENCES}

Asselineau, J. (1962): The bacterial lipids. Hormann, Paris. 372 p.

DRAPER, P. AND ReEs, R. J. W. (1973): The nature of electron-transparent zone that surrounds Mycobacterium lepraemurium inside host cells. J. Gen. Microbiol., 77, 79-87.

Fregnan, G. B., Smith, D. W. and Randall, H. M. (1962): A mutant of a scotochromogenic Mycobacterium detected by colony morphology and lipid studies. J. Bacteriol., 83, 828-836.

Furuchi, A. AND Tokunaga, T. (1972): Nature of the receptor substance of Mycobacterium smegmatis for $\mathrm{D}_{4}$ bacteriophage adsorption. J. Bacteriol., 111, 404-411.

Goren, M. B. (1972): Mycobacterial lipids: selected topics. Bacteriol. Rev., 36, 33-64.

Goren, M. B., McClatchy, J. K., Martens, B. and Brokl, O. (1972): Mycoside C: behaviour as receptor site substance for mycobacteriophage $\mathrm{D}_{4}$. J. Virol., 9, 999-1003.

Goren, M. B., BrokL, O. ANd Schaefer, W. B. (1974): Lipids of putative relevance to virulence in Mycobacterium tuberculosis: phthiocerol dimycocerosate and the attenuation indicator lipid. Infect. Immunity, 9, 150-158.

Kondo, E. AND KANAI, K. (1972): Further demonstration of bacterial lipids in Mycobacterium bovis harvested from infected mouse lungs. Japan. J. Med. Sci. Biol., 25, 105-122.

Kondo, E. AND KanaI, K. (1974): Further studies on the increase in cholesterol ester content of the lungs of tuberculous mice. Japan. J. Med. Sci. Biol., 27, 59-65.

Kondo, E. AND KANAI, K. (1976a): An attempt to cultivate mycobacteria in simple synthetic liquid medium containing lecithin-cholesterol liposome. Japan. J. Med. Sci. Biol., 29, 109-121.

Kondo, E. AND Kanar, K. (1976b): Accumulation of cholesterol esters in macrophages incubated with mycobacteria in vitro. Japan. J. Med. Sci. Biol., 29, 123-137.

Kondo, E. AND KANAI, K. (1976c): Virulence and immunogenicity of mycobacteria. Proceedings of the 11th meetings of Tuberculosis Panel, U.S.-Japan Cooperative Medical Science Program, 233-253.

RANDALl, H. M. AND SMith, D. W. (1964): Characterization of mycobacteria by infrared spectroscopic examination of their lipid fractions. Zentr. Bacteriol., I., Referate, 194, 190-201.

RAZIN, S. AND SHAFER, Z. (1969): Incorporation of cholesterol by membranes of bacterial L-phase variants. With an appendix. On the determination of L-phase parentage by the electrophoretic patterns of cell proteins. J. Gen. Microbiol., 58, 327-339.

Schubert, K., Kaufman, G. ANd Hörhold, C. (1969): Veresterung von Steriren mit Fettsauren und mit Bernstein Säure in Mykobakterien. Biochim. Biophys. Acta, 176, 163-169.

Smith, D. W., Randall, H. M., Maclennan, A. P. And Lederer, E. (1960): Mycosides; a new class of type-specific glycolipids of mycobacteria. Nature, 186, 887-888.

Steenken, W. AND Gardner, L. U. (1946): History of H37Ra strain of tubercle bacilli. Am. Rev. Tuberc., 54, 62-66.

Stuart, A. E. AND SMITh, I. I. (1974): Histological effects of lipids on the liver and spleen of mice. J. Pathol., 115, 63-71.

WERB, Z. AND CoHN, Z. A. (1972): Cholesterol metabolism in the macrophages. III. Ingestion and intracellular fate of cholesterol and cholesterol esters. J. Exptl. Med., 135, 21-44. 